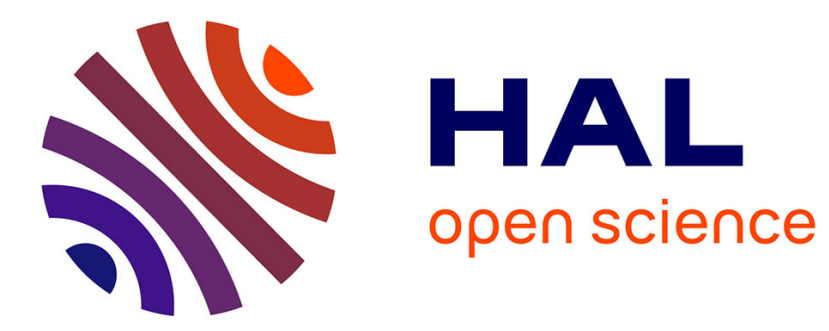

\title{
Fuel Pyrolysis through Porous Media: Coke Formation and Coupled effect on Permeability
}

Guillaume Fau, Nicolas Gascoin, Philippe Gillard, Marc Bouchez, Johan

Steelant

\section{- To cite this version:}

Guillaume Fau, Nicolas Gascoin, Philippe Gillard, Marc Bouchez, Johan Steelant. Fuel Pyrolysis through Porous Media: Coke Formation and Coupled effect on Permeability. Journal of Analytical and Applied Pyrolysis, 2012, 95, pp.180-188. 10.1016/j.jaap.2012.02.005 . hal-00705549

\section{HAL Id: hal-00705549 \\ https://hal.science/hal-00705549}

Submitted on 7 Jun 2012

HAL is a multi-disciplinary open access archive for the deposit and dissemination of scientific research documents, whether they are published or not. The documents may come from teaching and research institutions in France or abroad, or from public or private research centers.
L'archive ouverte pluridisciplinaire HAL, est destinée au dépôt et à la diffusion de documents scientifiques de niveau recherche, publiés ou non, émanant des établissements d'enseignement et de recherche français ou étrangers, des laboratoires publics ou privés. 


\section{Accepted Manuscript}

Title: Fuel Pyrolysis through Porous Media: Coke Formation and Coupled effect on Permeability

Authors: G. Fau, N. Gascoin, P. Gillard, M. Bouchez, J. Steelant

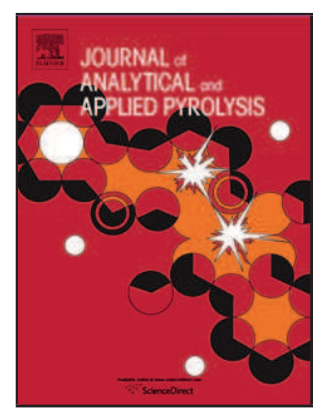

PII:

S0165-2370(12)00026-5

DOI: doi:10.1016/j.jaap.2012.02.005

Reference: JAAP 2714

To appear in: J. Anal. Appl. Pyrolysis

Received date: 24-10-2011

Revised date: 11-1-2012

Accepted date: 6-2-2012

Please cite this article as: G. Fau, N. Gascoin, P. Gillard, M. Bouchez, J. Steelant, Fuel Pyrolysis through Porous Media: Coke Formation and Coupled effect on Permeability, Journal of Analytical and Applied Pyrolysis (2010), doi:10.1016/j.jaap.2012.02.005

This is a PDF file of an unedited manuscript that has been accepted for publication. As a service to our customers we are providing this early version of the manuscript. The manuscript will undergo copyediting, typesetting, and review of the resulting proof before it is published in its final form. Please note that during the production process errors may be discovered which could affect the content, and all legal disclaimers that apply to the journal pertain. 


\title{
Fuel Pyrolysis through Porous Media:
}

\section{Coke Formation and Coupled effect on Permeability}

\author{
G. Fau ${ }^{1 *}$, N. Gascoin ${ }^{1}$, P. Gillard ${ }^{1}$, M. Bouchez ${ }^{2}$ and J. Steelant ${ }^{3}$ \\ ${ }^{1}$ University of Orléans, 63, avenue de Lattre de Tassigny - 18000 Bourges, France \\ ${ }^{2}$ MBDA-France, 18 rue Le Brix - 18000 Bourges, France \\ ${ }^{3}$ European Space Research and Technology Centre, Keplerlaan 1, 2201 AZ Noordwijk, The \\ Netherlands \\ *Corresponding author: Fax: +33 248238 471; Tel.: +33 248238 088; \\ Email: guillaume.fau@univ-orleans.fr
}

\begin{abstract}
The development of hypersonic vehicles (up to Mach 10) leads to an important heating of the whole structure. The fuel is thus used as a coolant. It presents an endothermic decomposition with possible coke formation. Its additional permeation through the porous structure involves internal convection. This implies very complex phenomena (heat and mass transfers with chemistry). In this paper, the n-dodecane pyrolysis is studied through stainless steel porous medium up to $820 \mathrm{~K}$ and 35 bar (supercritical state). The longitudinal profiles of chemical compositions inside the porous medium are given thanks to a specific sampling technique with off-line Gas Chromatograph and Mass Spectrometer analysis. By comparison with previous experiments under plug flow reactor, the conversion of dodecane is higher for the present experimental configuration. The pyrolysis produces preferentially light gaseous species, which results in a higher gasification rate for a similar pyrolysis rate. The effects of the residence time and of the contact surface area are demonstrated. The transient changes of Darcy's permeability are related to the coke formation thanks to previous experimental relationship with methane production. A time shift is observed between coke chemistry and
\end{abstract}




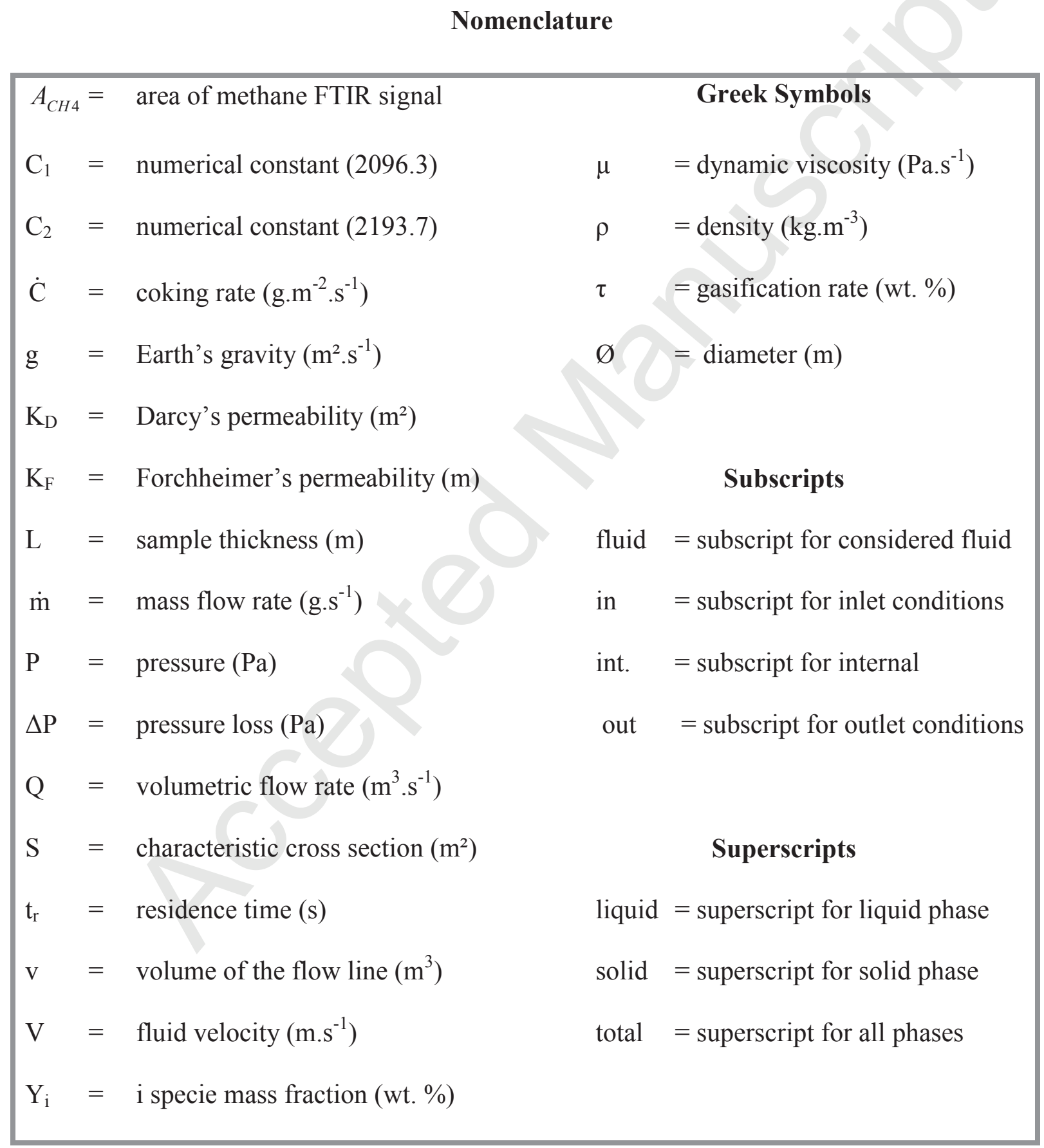

\section{Nomenclature}

Keywords: Permeation, pyrolysis, porous medium, coke, active cooling, catalytic effect. 


\section{Introduction}

High speed vehicles are facing large thermal load because of the high velocity and because of the accumulated combustion heat. To challenge this problem, several cooling systems have been developed. Two major axis have been particularly studied: the material withstanding against high pressures and high temperatures on the one hand and a reliable cooling of the combustion chamber on the other hand [1-3]. The European ATLLAS project (Aerodynamic and Thermal Load interactions with Lightweight Advanced materials for high Speed) supported by the European Space Agency is investigating this topic, notably the transpiration through Ceramic Matrix Composite (CMC) structures. This cooling technique presents difficulties, which needs to be investigated. The coolant can react with the material (catalytic effect) and the coke formation can modify the structure's permeability [4]. As a result, the coupling of heat and mass transfer is directly impacted by the chemistry and such phenomenon need to be more understood. For this reason, the present work presents experiments in order to investigate the fuel pyrolysis through porous media and the associated phenomena (permeation, catalysis and coke production).

\section{1. Permeation through porous media}

The permeation process is a complex phenomenon widely studied in various research areas such as nuclear power [5] or geology [6]. This particular phenomenon is treated experimentally $[7,8]$, numerically $[9,10]$ or mathematically [11]. A first approach to understand this specific phenomenon is to express the well-known Darcy's law:

$$
\mathrm{Q}=\mathrm{KS} \frac{\Delta \mathrm{P}}{\rho \cdot \mathrm{g} \cdot \mathrm{L}}
$$

This law is a linear part (only available for laminar flow) and should be completed by an additional one (for so-called turbulent flow). Thus, the next equation follows [12]: 


$$
\frac{\Delta \mathrm{P}}{\mathrm{L}}=\mu \cdot \frac{\mathrm{V}}{\mathrm{K}_{\mathrm{D}}}+\rho \cdot \frac{\mathrm{V}^{2}}{\mathrm{~K}_{\mathrm{F}}}
$$

This law (known as the Brinkman's equation) can be derived and expressed with a large panel of relationships according to the application fields. Additional terms, like the Stokes term [13], can be added and the pressure loss can be written in several ways [14]. Depending on the selected expression, the fluid properties are given either by inlet or mean conditions. The permeation mainly depends on the material structure which can be considered at different scales (macro, micro and also meso scale) [15]. Due to the complexity of composite materials, it is chosen in this paper to consider metallic samples which are homogeneously made of stainless steel agglomerated particles.

\section{I . 2. Pyrolysis of hydrocarbons and hypersonic conditions}

The general scheme of pyrolysis is composed of the following successive and simultaneous reactions: random scission (the chain scission produces the free radicals), H-abstraction and beta scission (production of unsaturated compounds with one or two terminal double bond) [16]. These reactions appear in primary and secondary mechanisms. The degree of decomposition is highly dependent on the operating conditions (temperature, pressure, type of flow, nature of reactor) [17-21]. Thermal cracking of hydrocarbons have been widely studied in petrochemical industry [18,22-26]. It appears than the bigger the molecule, the higher the number of reactions which occur. Considering dodecane pyrolysis, the number of reactions largely overpasses 1000. Light hydrocarbons like methane, acetylene or ethylene are produced such as heavy compounds (benzene) and even more complex ones (notably Polycyclic Aromatics Hydrocarbons - $\mathrm{PAH}$ - such as naphthalene and pyrene) which are precursors of solid carbon formation [27]. This coke may interfer with the permeation process by lowering the porosity and reducing the contact surface between coolant and solid surface. Thus, the comprehension of the reaction pathway is one of the key to monitor and control such a 
phenomenon. Last element to consider is that in real conditions, the fuel temperature can reach $1500 \mathrm{~K}$ and the pressure can be higher than 30 bar. This leads the fuel to be at supercritical state. To the authors' knowledge, no study does exist on fuel pyrolysis under permeation configuration. The challenge of the present work is thus to achieve supercritical fuel pyrolysis in porous media and to monitor the longitudinal chemical composition profile inside the structure thanks to appropriate sampling technique.

\section{3. Surface catalytic effect and coke formation}

Some interactions between the molecules constituting the wall and the fluid may happen (surface reactions). This could modify strongly the reaction pathway and it can lead to a potential higher production of coke (which justifies considering specifically this point) [2830]. Considering this element, the treatment of the inner wall could have a critical impact on the fuel degradation. It was shown that an oxygen treatment generally enhances the catalytic activity (considering a metallic reactor) and leads to a higher production of coke [28,31]. The treatment by hydrogen sulphide permits to inhibit this phenomenon and to act as passivation. A recent study also showed that coating the inner wall with zeolites or with a ceramic-like binder both limit the coke production, enhance the fuel decomposition and, consequently, increase the heat sink capacity of the material [32]. Hence, the choice of the wall material is a critical point and has to be considered with respect to the surface catalytic effect. In the present work, some investigations will be proposed in order to estimate its impact on the distribution of pyrolysis products.

Finally, the present study aims at investigating fuel pyrolysis in porous media to determine the intrinsic effect of the permeable material compared to existing data on fuel pyrolysis in open tubular reactor. The effects of the contact surface, of the residence time, of the catalytic effect and of heat and mass transfers are of interest. This work is even more important since it is the first frontier work, to the author's knowledge, between pyrolysis, catalysis and filtration. 
The final aim is to be able predicting the coke formation and its effect on permeability in order to ensure the cooling efficiency of regenerative cooling technique. Scientifically, major progresses are waited on the understanding of coupled heat and mass transfer with chemistry by experimentally observing the heterogeneous profiles of permeation and of pyrolysis inside the porous medium.

\section{II . 1. Experimental bench}

\section{Material and method}

A high pressure and high temperature experimental bench $(1200 \mathrm{~K}, 60 \mathrm{bar})$ is used with a novel sampling technique to investigate the pyrolysis products distribution as a function of operating conditions. The setup is derived from the one of the COMPARER project (COntrol and Measure of PArameters in a REacting stReam) conducted by the University of Orléans and MBDA-France [29]. The liquid fuel is injected by a pump (80 bar, 0.5 g. $\left.\mathrm{s}^{-1}\right)$ inside a chemical reactor, which is placed in a furnace. This reactor is made of a preheated stainless steel tubular reactor $\left(\varnothing_{\text {int. }}=3.45 \mathrm{~mm}\right.$, length $\left.=550 \mathrm{~mm}\right)$ and of a dedicated cell $\left(\varnothing_{\text {int }}=30 \mathrm{~mm}\right.$, length $\left.=100 \mathrm{~mm}\right)$ in which the porous medium is inserted (filtration diameter of $16 \mathrm{~mm}$ only). A cooling reactor $\left(\varnothing_{\text {int. }}=3.45 \mathrm{~mm}\right.$, length $\left.=300 \mathrm{~mm}\right)$ is placed at the cell outlet to conduct the fluid out of the furnace before being analyzed transiently by Infra Red spectrometry (FTIR) for the gas phase and before being sampled. These samples under liquid and gas phases at ambient conditions are a posteriori analyzed separately by both Gas Chromatograph (GC) and Mass Spectrometer (MS). Further details on the bench description can be found in previous work $[33,34]$.

An improvement of the described bench consists on a novel technique of sampling (Figure 1). This allows obtaining the longitudinal distribution of pyrolysis mixture composition inside the permeable medium. First, sampling tubes have been placed as close to 
the medium as possible. The porous sample is drilled to get samples in its middle. A good contact is ensured to get reliable samples. A complex system of small size cylinders, valves and pump has been designed to ensure the smallest possible residence time between the sampling point and the cylinder, a fast filling of these cylinders, a sufficient sample quantity for the GC/MS analysis, a good synchronization of the sampling during the test and finally the good representativeness of the samples compared to the real process itself. The dynamics of this system is of importance to have a "non intrusive" device. The following sampling locations are noted for this work: upstream (point A, Figure 1), inside (point B, Figure 1) and downstream (point C, Figure 1). The distance between each point is equal, around $1.5 \mathrm{~mm}$. Considering the test cell itself, further information can be found in previous work [33].

\section{Figure 1 should be placed here}

\section{II . 2. Test methodology}

N-dodecane (VWR, Rectapur 99\% of purity) is used for these experiments because it is known as a good kerosene surrogate. It has been extensively studied by the authors in numerous pyrolysis configurations $[4,29,30]$. Thus, comparison with existent experimental data can be easily made. A stainless steel sample $(\varnothing=30 \mathrm{~mm}$, filtration diameter $=16 \mathrm{~mm}$ thickness of $3 \mathrm{~mm}$ ) is preferred as a porous medium compared to composite material because it is well characterized. Its implication in coke enhancing was notably demonstrated by PRISME team in tubular reactor configuration [30]. Nevertheless, no data are available for permeation configuration so that these works will provide new information on stainless steel surface effect and be compared with precedent results. Its class of porosity number 3 (the socalled $\mathrm{SS}_{3}$, Figure 2) presents an overall porosity of $30 \%$, pores diameter of $4.1 \mu \mathrm{m}$ and grain diameter of $14.1 \mu \mathrm{m}$ [33]. SEM (Scanning Electron Microscope) images with EDS (Energy Dispersive Spectroscopy) analysis are conducted after the tests on the porous sample to determine the nature of the deposited carbon. Initial composition is given in Figure 2. 
The tests are conducted with successive stationary thermal plateaus. For a given mass flow rate $\left(65 \mathrm{mg} \cdot \mathrm{s}^{-1}\right)$, the setup furnace temperature is increased from ambient to $750 \mathrm{~K}$ and then by $50 \mathrm{~K}$ steps after thermal stabilization (about 45 minutes for each plateau). The outlet pressure is regulated (35 bar) and the inlet pressure is measured. The samples are realized for the three locations during $10 \mathrm{~s}$ at the end of each thermal plateau. Three setup furnace temperatures are studied $(750 \mathrm{~K}, 800 \mathrm{~K}$ and $850 \mathrm{~K})$, which corresponds respectively to maximum fluid temperatures of $725 \mathrm{~K}, 765 \mathrm{~K}$ and $820 \mathrm{~K}$. The gasification rate (quantity of produced gas divided by the injected fuel quantity) and the pyrolysis rate (also noted the conversion rate, i.e. the quantity of decomposed dodecane divided by the initial dodecane quantity) are determined by mass balance for each thermal plateau. The gas and liquid phases are analyzed separately for each sample. Some species can be found under both phase due to saturated vapour pressure. Grouping liquid and gas phase analysis, the mass fraction of each species are expressed by Eq. 3 where $Y_{i}^{\text {liquid }}$ denotes the mass fraction of the specie in the liquid phase and $\mathrm{Y}_{\mathrm{i}}^{\mathrm{gas}}$ the mass fraction in the gas phase.

$$
Y_{i}=Y_{i}^{\text {liquid }} \times(1-\tau)+Y_{i}^{\text {gas }} \times \tau
$$

The permeabilities of Darcy and Forchheimer are computed thanks to the pressure drop and to the flow rate monitored as a function of time, using the Eq. 2. Eq. 2 is rewritten in conformity with the international norm ISO 4022 (Eq. 4) and the fluid properties are the mean one between the inlet and outlet conditions.

$$
\frac{\Delta \mathrm{P}}{\mathrm{L} \cdot \mu \cdot \mathrm{V}}=\frac{1}{\mathrm{~K}_{\mathrm{D}}}+\frac{\rho \cdot \mathrm{V}}{\mu \cdot \mathrm{K}_{\mathrm{F}}}
$$

A linear relationship (Eq. 5) derived from previous experiments with stainless steel tubular reactors [4] has been used in this work to determine the coke formation as a function of time on the basis of methane production which is monitored by FTIR spectrometer at the process 
outlet. This law will be used later in the paper to analyze and to explain the variations of

Darcy's permeability of the material during the coking activity.

$$
\mathrm{m}_{\mathrm{C}}=\frac{\mathrm{A}_{\mathrm{CH}_{4}}-\mathrm{C}_{1}}{\mathrm{C}_{2}}
$$

\section{Results and discussion}

\section{III . 1. Distribution of pyrolysis product yields}

The pyrolysis tests are conducted under the stationary thermal conditions described previously. The samplings are done for fluid temperatures of $725 \mathrm{~K}, 765 \mathrm{~K}$ and $820 \mathrm{~K}$. For points $\mathrm{A}$ and $\mathrm{B}$ (upstream and inside the porous media), the samplings were only made for the two last temperatures because negligible pyrolysis was observed for the first temperature.

Table 1 presents the mass composition of the pyrolysis mixtures. The authors precise that the precision is voluntary set at one hundredth in order to avoid the suppression of species which were detected in very low quantity. Nevertheless, the quantity lower than 0.1 wt.\% should be considered for illustrative purpose mainly. First, it can be noted that the decomposition of dodecane varies not only with temperature but also as a function of the location in the porous medium (points A to C). The conversion rate increases along the flow. This result is in qualitative agreement to that obtained under plug flow reactor on COMPARER project [29-30]. This is directly related to the residence time distribution and to the convective heat transfer. Considering the pyrolysis products (Table 1), n-dodecane is preferentially decomposed into light species at the entrance of the cell and at the process outlet (respective predominant species: butane / ethane at $765 \mathrm{~K}$ and ethane / propylene at $820 \mathrm{~K})$. Alkanes are found in majority compared to alkenes, contrary to what was observed generally in plug flow reactor during previous experiments [29-30]. This is due to the heat transfers, which are enhanced in the porous material due to the high contact surface. The flow behaviour in porous medium is closer to the one in perfectly stirred reactor (homogeneous 
flow) than to the plug flow reactor (spatial heterogeneity). The $\mathrm{H}$ over $\mathrm{C}$ atoms mass ratio tends to one sixth for all the alkenes; it is one twelfth for benzene and it starts from one third for methane to around 0.181 for dodecane. It was found in previous work [29] that the H over $\mathrm{C}$ ratio increases (higher than 0.18 ) when the heat transfers increase, which indicates a higher alkanes production. The present results (Table 1) thus confirm this observation. Indeed, a higher proportion of ethane than ethylene or propane than propylene are found whatever the temperature or the axial position, with a $\mathrm{H}$ over $\mathrm{C}$ ration always higher than 0.18 . Additional comments will be provided on this point at the end of this section with Figure 3.

Table 1 should be placed here

A different repartition is found (Table 1) inside the porous medium (preponderant midweigh species: hept-1-ene $765 \mathrm{~K}$ and hex-1-ene and butane at $820 \mathrm{~K}$ ). Several assumptions can be made to explain these facts.

First, the light compounds are sampled preferentially due to a bad sampling technique and the absence of heavy species at the inlet is the consequence. Nevertheless, this is not the most possible reason because heavy compounds are found for the samples related to point B with the same sampling technique. It is thus supposed that the sampling technique provides reliable samples, which are representative of the test conditions. It must be noted that samples at the outlet are satisfactory because they are obtained with a validated methodology which is used since 2005 (6 years of intensive pyrolysis work).

Second, this could be attributed to the chemical diffusion of the species in the porous media. The lack of light species at point B is due to their higher filtration speed. Nevertheless, under steady-state conditions, this effect should be low. Some numerical computations have been done for another project and only small discrepancies in similar conditions have been found between simulations with and without chemical diffusion. 
Third, the radial heterogeneity of the thermal, hydraulic and chemical parameters implies

that the samples are mostly representatives of the specific locations where they are made and not of the corresponding longitudinal coordinate. This is a possibility which can not be easily investigated by experimental test. For this reason, numerical simulation should be conducted in a near future.

Finally, the differences can be related to the coking activity which modifies the surface effect (heterogeneous reactions) and the heat and mass transfers. In case of deactivation of the surface or of the saturation of the sites, a limitation of the surface catalytic effect could be encountered. Such dynamic was already found considering other fuel [28]. Thus, this assumption must be correlated with coke analysis and to the formation and consumption of some species (acetylene, ethylene, benzene). The benzene, toluene and p-xylene formation increases for a temperature of $765 \mathrm{~K}$ at point $\mathrm{B}$, and then decreases at $820 \mathrm{~K}$ (Table 1). This can sign the coke formation (in a first time, production of coke precursors, and then an aggregation of those ones to form solid carbon). The heat transfers are reduced and the pyrolysis is slowed down (less formation of light compounds). On the contrary, it can also be assumed that the light species, precursors of coke, begin to react and form the secondary species involved in the formation of carbon deposit (decrease also shown at point B, Table 1). As a consequence, this analysis remains difficult on the basis of these first results and, again, numerical simulation would be of great interest. However, the amplitudes of the variations are quite small and the accuracy of the measures could be responsible for these changes regarding benzene, toluene and p-xylene for example.

The chemical spatial profiles of group species can be further discussed. It is clear that the part, where chemical reactions are the most intense, is the second half of the porous medium. Significant fall of light species mass fractions $\left(C_{1}\right.$ to $\left.C_{3}\right)$ can be seen at the point $B$ for the two temperature plateaus. Regarding mid-weigh species $\left(\mathrm{C}_{4}-\mathrm{C}_{6}\right)$ the production is quite similar 
even if the drop between A and B is less important. The profile of heavy precursors of coke is comparable for a temperature of $820 \mathrm{~K}$ but is clearly different for the $765 \mathrm{~K}$ thermal stage.

Due to the very low mass fractions, the interpretation of such results remains very difficult. Nevertheless it could be assumed that this profile is due to the chemical induction delay which depends on the fluid temperature. But, this can not fully explain such an activity. Spatially, point $\mathrm{A}$ and $\mathrm{B}$ are very close so that the fluid temperature is identical. The presence of the porous medium may increase the residence time and, consequently, the decomposition rate. The high difference between the profiles may also be linked to a catalytic activity of the porous medium. To investigate the intrinsic effect of the porous media, a comparison can be made with previous COMPARER data obtained under open tubular reactor configurations [30]. The comparison is conducted for the samples issued from the point C. For the plug flow reactor (pressure $=10-60$ bar, residence time $=50-100 \mathrm{~s}$ and mass flow rate $=50$ $100 \mathrm{mg} . \mathrm{s}^{-1}$ ), the dodecane decomposition rate is lower than $10 \mathrm{wt} . \%$ for a furnace temperature close to $850 \mathrm{~K}$ instead of about $48 \mathrm{wt} . \%$ for the porous sample (Table 2). Indeed, even by considering a lower pressure (10 bar), a lower mass flow rate $\left(50 \mathrm{mg} . \mathrm{s}^{-1}\right)$ and consequently a theoretical higher decomposition, the pyrolysis rate is more than five times lower for plug flow experiment.

\section{Table 2 should be placed here.}

To reach a comparable decomposition, the considered temperature must be far higher (over $1250 \mathrm{~K}$, Table 3). The species repartition is quite different: more light and mid-weighted species are found for plug flow reactor experiments while heavy species and, in particular, coke precursors are more present in the permeation configuration (Table 3). So, the increase of the dodecane decomposition and its different profile compared with plug flow reactor may be explained by the presence of the porous medium (i.e. increase of the residence time, of the contact surface and of the catalytic effect). 
Finally, the gasification and pyrolysis rate have been plotted for the three temperatures and

three sampling locations (points A to C) (Figure 3). A qualitative parabolic trend corresponding to the plug flow reactor is given from the COMPARER project results (full black curve, Figure 3). The experimental data points obtained for the porous flow are close to the line. This line (from $[0 \% ; 0 \%]$ to $[100 \% ; 100 \%]$ ) means that $100 \%$ of the pyrolysis products are found under gas phase at ambient conditions. This clearly highlights the difference between the two types of flow. The strong gas formation, in case of porous flow, is mainly due to the higher contact surface between the fluid and the overall reactor because of the presence of the porous medium. The residence time also explains the differences but it is not possible to estimate the one in porous media for compressible reactive fluid without numerical simulation support.

Additional computations were done for the same operating conditions than the experiments but using a perfectly stirred reactor configuration with the n-dodecane pyrolysis mechanism furnished by Dahm [35]. The results show strong similarities between PSR and porous flow compositions while PSR computations are not able to represent the multiphysic coupled phenomena involved in open tubular reactor [29]. Consequently, the permeation through porous media seems to present more similarities with PSR like conditions than with plug flow ones.

\section{Figure 3 should be placed here}

\section{III . 2. Coking activity}

At the end of the pyrolysis tests, the central zone on the porous sample -which corresponds to the fluid flow cross-section- is clearly covered on the side of point A by a black layer of about $0.3 \mathrm{~mm}$ (Figure 4a). No carbon deposit is found on the opposite side (point C). This coke formation has been observed by SEM and an accumulation of solid micrometric particles 
is found. and which mean diameter is of the order of $1 \mu \mathrm{m}$ (Figure 4b). After surface cleaning, another SEM images clearly shows a clogging of the pores by similar particles with much smaller diameter (of the order of $0.1 \mu \mathrm{m}$ or less) (Figure 4c). The particles of the permeable sample which are visible on the Figure 4c are covered by a carbon layer which composition is not so different from the one of the solid coke particles. Indeed, the coke particles at the surface are almost constituted of pure carbon (96 wt.\% with 4 wt.\% of O atoms, Figure 4) while the stainless steel particles reveal a higher carbon content (about $20 \mathrm{wt} . \%$ instead of 7 wt.\% initially, Figure 2). These $20 \mathrm{wt} \% \%$ are found with an increase of about $1 \mathrm{wt} . \%$ of O atoms (2.34 wt.\% instead of 1.31 wt.\% initially). The $\mathrm{C} / \mathrm{O}$ ratio is thus about 24 for the solid coke particles and around 20 for the coke at the stainless steel particles surface (if this $1 \mathrm{wt} . \%$ is strictly attributed to the coke formation, which is questionable). This slight difference may be related to the origin of formation of the coke (catalytic, i.e. inside the porous medium, and pyrolytic, i.e. at the surface) as it has been studied in previous work [4]. Nevertheless, the differences are too small to be quantitatively interpreted and these results should be completed in a future work to determine quantitatively the effect of stainless steel and of the contact surface area in the process. It can only be mentioned that the presence of carbon layer on the particles of stainless steel demonstrates the implication of the solid material in heterogeneous reactions.

\section{Figure 4 should be placed here}

In addition to this macroscopic quantification, the mass of carbon deposit can be approximated as a function of time thanks to a previous experimental relationship as described in section II.B. The methane formation has been monitored by FTIR measures during the test and the estimated coke mass is given with and without its normalisation to the final mass measured at the end of the test (Figure 5). Indeed, directly using the relationship as mentioned in section II.B gives a total amount of coke of $3 \mathrm{~g}$ at the end of the experiment 
while only $0.46 \mathrm{~g}$ are detected. This over-prediction can be related to the contact surface area differences between the porous flow and the plug flow reactor. As a consequence, it is preferred to normalise the coke mass evolution to the maximum measured one, that is to say $0.46 \mathrm{~g}$. This carbon deposit formation is also given as a function of temperature (Figure 6). Both parameters are roughly related except when the temperature reaches a thermal plateau ( $725 \mathrm{~K}, 765 \mathrm{~K}$ and $820 \mathrm{~K}$ ). The mass of coke increases during these plateaus because of the time of experiment.

\section{Figure 5 should be placed here.}

\section{Figure 6 should be placed here.}

\section{III . 3. Clogging effect of the coke formation}

The formation of coke deposit inside the pores of the permeable material and on its surface modifies the filtration of the fluid. During the initial heating of the system from ambient to $700 \mathrm{~K}$, before the $\mathrm{n}$-dodecane starts to pyrolyse, a constant value of $1.96 .10^{-13} \mathrm{~m}^{2}$ is found for the Darcy's permeability. This is in complete agreement with the value found at ambient condition with a nitrogen flow [33]. Then, the transient darcian value computed during the experiment is given in Figure 7. The vertical straight lines represent the sampling times at the point A. Some decreases are found up to 2 to 3 orders of magnitude, which signify strong clogging of the porous medium. In addition, several sudden increases are observed at the locations marked by the vertical lines. On the basis of Figure 7, it is assumed that making a sampling upstream the porous medium impacts the flow. When opening the sampling line to the cylinder, the inlet pressure briefly becomes lower than the outlet one so that the flow is reversed (because of a lower pressure in the cylinders than in the process). The porous medium is temporarily cleaned and solid particles are removed. As a result, the Darcy's permeability increases. 
The effect of the coke formation on the Darcy's permeability is mainly due to the accumulation of carbon particles inside the pores of the stainless steel sample because the permeability of the coke deposit on a surface (as observed on point A) has been determined previously to be about $10^{-8} \mathrm{~m}^{2}$ [36]. Thus, this high value (in comparison to the original permeability of the medium) should not impact the measure of the $K_{D}$. This conclusion is reinforced by the determination of mass of carbon deposit which is detected at the surface (8.66 mg) compared to the one inside the sample $(460 \mathrm{mg})$. The coke quantity is 50 times more important in the medium than at its surface. Considering the density of solid carbon, this corresponds to a volume of about $0.230 \mathrm{~cm}^{3}$, which can be compared to the volume of pore in case of a porosity of $30 \%$. (about $0.645 \mathrm{~cm}^{3}$ ). Thus, the coke limits this volume by about $30 \%$ which may have an important impact on the filtration (Figure 7).

\section{Figure 7 should be placed here}

The surface weight information can also be used to determine the coking rate. To provide a relationship between permeability variations and chemical phenomena, the coke formation is a good witness of the process (Figure 8). The coking rate is calculated using the following equation:

$$
\dot{\mathrm{C}}=\frac{\mathrm{m}_{\mathrm{C}}}{\mathrm{S} \times \mathrm{t}_{\mathrm{r}}}
$$

Where the residence time is varying during the experiment and it is estimated by:

$$
\mathrm{t}_{\mathrm{r}}=\frac{\rho \times \mathrm{v}}{\dot{\mathrm{m}}_{\text {fluid }}}
$$

Two qualitative similar behaviors are found for the coking rate and for the rate of change in Darcian permeability (Figure 8). The production of coke limits directly the filtration surface. This has an impact on heat and mass transfer because the residence time decreases and it should lead to a lower decomposition. Nevertheless, such comportment is not clearly understood and further work is requirement to confirm these preliminary results. This 
relationship between coke formation and its modification of the permeability is of great interest in case of active cooling in order to predict the modification of cooling efficiency. In addition, a time delay may appear between both curves because the arrows are not all vertical and their slope is decreasing, which means that the clogging process slows down but the cleaning effect of the sampling at point A modifies the dynamics of the system and this conclusion remains questionable.

\section{Figure 8 should be placed here}

\section{Conclusion}

Regenerative cooling by fuel permeation through porous material are some of the available efficient methods to face the thermal issue of hypersonic vehicles. Instead of using inert flow, as it is often seen in open literature for simplification reason, $\mathrm{n}$-dodecane pyrolysis has been achieved in the present work through stainless steel porous sample under supercritical state ( $820 \mathrm{~K}$ and 35 bar). A specific sampling technique has been developed to analyze the chemical composition distribution of the pyrolyzed fuel through the longitudinal coordinate of the permeable medium. The monitoring of chemical species enables to understand that the major part of the pyrolysis is observed in the second half of the medium. A coke formation is principally observed at the inlet surface of the solid and also inside the pores. An analysis (C and $\mathrm{O}$ atoms content) proves the dual origin of this coke deposit (catalytic and pyrolysis effects). The relationship between the solid carbon formation and the changes of Darcy's permeability is investigated. A time shift between both of them is proposed. This is of interest to characterize the dynamics of coupled phenomena. In terms of pyrolysis, the effect of porous medium is clear since the products which were found are in majority gaseous at ambient conditions. This is different from the results obtained under plug-flow reactor for which the gasification rate was lower than the present one for the same pyrolysis rate and with similar conditions. The pyrolysis in porous sample can be modeled by perfectly stirred reactor 
because of the residence time and large contact surface between the solid and the fluid. This

work will now be extended to investigate in more details the catalytic effect by using composite media and other materials in same operating conditions. In addition, numerical simulation will be achieved to furnish further results on the spatial heterogeneity of the thermal, hydraulic and chemical parameters.

\section{Acknowledgments}

This work was supported by the ESA-ESTEC, Contract no.: 3-12861/09/NL/PA. The authors would like to sincerely thank B Le Naour and J Bertrand from MBDA-France for their help involving this project. The highly valuable work of D. Blanc and D. Courilleau involving the measurement cell of PRISME bench has been greatly appreciated. The authors also would like to thank the help of J.-C. Hargé for the SEM and EDS measurements.

[1] J. Steelant, ATLLAS: Aero-Thermal Loaded Material Investigations for High-Speed Vehicles, 15th AIAA International Space Planes and Hypersonic Systems and Technologies Conference. (2008) AIAA 2008-2582.

[2] M. Bouchez, E. Dufour, F. Cheuret, J. Steelant, P. Grenard, J.A. Redford, et al., Material-Aero-Thermal Interaction Computations in the ATLLAS European Programme, 44th AIAA/ASME/SAE/ASEE Joint Propulsion Conference \& Exhibit. (2008) AIAA 2008-4670.

[3] J. Steelant, Achievements obtained on Aero-Thermal Loaded Materials for HighSpeed Atmospheric Vehicles within ATLLAS, 16th AIAA/DLR/DGLR International Space Planes and Hypersonic Systems and Technologies Conference. (2009) AIAA 2009-7225.

[4] N. Gascoin, P. Gillard, S. Bernard, M. Bouchez, Characterisation of coking activity during supercritical hydrocarbon pyrolysis, Fuel. Process. Technol. 89 (2008) 14161428 .

[5] T. Hino, E. Hayashishita, Y. Yamauchi, M. Hashiba, Y. Hirohata, A. Kohyama, Helium gas permeability of $\mathrm{SiC} / \mathrm{SiC}$ composite used for in-vessel components of nuclear fusion reactor, Fusion Eng. Des. 73 (2005) 51-56. 
[6] G.X. Wang, P. Massarotto, V. Rudolph, An improved permeability model of coal for coalbed methane recovery and CO2 geosequestration, Int. J. Coal Geol. 77 (2009) $127-136$.

[7] L.R. Tully, A. Omar, J.N. Chung, B.F. Carroll, Fluid flow and heat transfer in a liquid rocket fuel injector, 41st AIAA/ASME/SAE/ASEE Joint Propulsion Conference \& Exhibit. (2005) AIAA 2005-4127.

[8] T. Langener, J. Von Wolfersdorf, T. Laux, J. Steelant, Experimental Investigation of Transpiration Cooling with Subsonic and Supersonic Flows at Moderate Temperature Levels, 44th AIAA/ASME/SAE/ASEE Joint Propulsion Conference \& Exhibit. (2008) AIAA 2008-5174.

[9] P. Murthy, P. Singh, Thermal dispersion effects on non-Darcy convection over a cone, Comput. Math. Appl. 40 (2000) 1433-1444.

[10] J.R. Riccius, A. Gernoth, D. Greuel, Coupled CFD analysis of hot gas and coolant flow in effusion-cooled combustion chambers, 41st AIAA/ASME/SAE/ASEE Joint Propulsion Conference \& Exhibit. (2005) AIAA 2005-4437.

[11] M.J. Kim, E.J. Park, Fully discrete mixed finite element approximations for nonDarcy flows in porous media, Comput. Math. Appl. 38 (1999) 113-129.

[12] S. Soller, C. Kirchberger, M. Kuhn, T. Langener, M. Bouchez, J. Steelant, Experimental Investigation of Cooling Techniques and Materials for Highspeed Flight Propulsion Systems, 16th AIAA/DLR/DGLR International Space Planes and Hypersonic Systems and Technologies Conference. (2009) AIAA 2009-7374.

[13] I.S. Ligaarden, M. Krotkiewski, K.A. Lie, M. Pal, D.W. Schmid, On the Stokes Brinkman Equations for Modeling Flow in Carbonate Reservoirs, 12th European Conference on the Mathematics of Oil Recovery. (2010).

[14] N. Gascoin, G. Fau, P. Gillard, M. Kuhn, M. Bouchez, J. Steelant, Comparison of two permeation test benches and of two determination methods for Darcy's and Forchheimer's permeabilities, J. Porous Media. 15 (2012).

[15] F. Zhou, N. Kuentzer, P. Simacek, S.G. Advani, Analytic characterization of the permeability of dual-scale fibrous porous media, Compos. Sci. Technol. 66 (2006) 2795-2803.

[16] A. Safarik, O.P. Strausz, The thermal decomposition of hydrocarbons. Part 1. nAlkanes (C 5), Res. Chem. Intermediat. 22 (1996) 275-314.

[17] F. Billaud, F. Baronnet, C.P. Gueret, Thermal coupling of methane in a tubular flow reactor: parametric study, Ind. Eng. Chem. Res. 32 (1993) 1549-1554.

[18] D.B. Murphy, R.W. Carroll, J.E. Klonowski, Analysis of products of hightemperature pyrolysis of various hydrocarbons, Carbon. 35 (1997) 1819-1823. 
[19] C.J. Chen, M.H. Back, R.A. Back, The Thermal decomposition of methane. I. Kinetics of the primary decomposition to $\mathrm{C} 2 \mathrm{H} 6+\mathrm{H} 2$; Rate constant for the homogeneous unimolecular dissociation of methane and its pressure dependence, Can. J. Chem. 53 (1975) 3580-3590.

[20] C.J. Chen, M.H. Back, R.A. Back, The themal decomposition of methane. II. Secondary reactions, autocatalysis and carbon formation; non-Arrhenius behaviour in the reaction of CH3, with ethane, Can. J. Chem. (1976).

[21] P. Zámostný, Z. Bělohlav, L. Starkbaumová, J. Patera, Experimental study of hydrocarbon structure effects on the composition of its pyrolysis products, J.Anal. Appl. Pyrol. 87 (2010) 207-216.

[22] J. Dunkleman, L.F. Albright, Pyrolysis of propane in tubular flow reactors constructed of different materials, in: Industrial and Laboratory Pyrolyses, Am. Chem. S, 1976: pp. 15-261.

[23] L.S. Kassel, The thermal decomposition of methane, J. Am. Chem S. 54 (1932) 39493961.

[24] J.P. Chakraborty, D. Kunzru, High pressure pyrolysis of n-heptane, J. Anal. Appl. Pyrol. 86 (2009) 44-52.

[25] P. Zhou, B.L. Crynes, Thermolytic reactions of dodecane, Ind. Eng. Chem. Proc.DD. 25 (1986) 508-514.

[26] F. Billaud, E. Freund, N-Decane pyrolysis at high-temperature in a flow reactor, Ind. Eng. Chem. Funda. 25 (1986) 433-443.

[27] O. Herbinet, P.M. Marquaire, F. Battin-Leclerc, R. Fournet, Thermal decomposition of n-dodecane: Experiments and kinetic modeling, J. Anal. Appl. Pyrol. 78 (2007) 419-429.

[28] M.A. Ghaly, B.L. Crynes, Reactor Surface Effects During Propylene Pyrolysis, in: Industrial and Laboratory Pyrolyses, Am. Chemi. S, 1976: pp. 13-218.

[29] N. Gascoin, Etude et mesure de paramètres pertinents dans un écoulement réactif,Editions Universitaires Européenes, 2010, ISBN13:978-6131501074, p.376. .

[30] G. Abraham, Etude et développement d'une méthode d'analyse par spectroscopie infrarouge appliquée à la pyrolyse d'hydrocarbures en conditions supercritiques et transitoires, Ph.D. Thesis. (2009), University of Orleans, France.

[31] B.L. Crynes, L.F. Albright, Pyrolysis of propane in tubular flow reactors. Kinetics and surface effects, Ind. Eng. Chemi. Proc. DD. 8 (1969) 25-31.

[32] J. Li, J. Zou, X. Zhang, W. Guo, Z. Mi, Catalytic cracking of endothermic fuels in coated tube reactor, Front. Chem. Eng. 2 (2008) 181-185. 
[33] N. Gascoin, High temperature and pressure reactive flows through porous media, Int. J. Multiphas. Flow. 37 (2011) 24-35.

[34] N. Gascoin, G. Fau, P. Gillard, M. Kuhn, M. Bouchez, J. Steelant, Benchmark of Experimental Determination Methods of Gas, 17th AIAA International Space Planes and Hypersonic Systems and Technologies Conference. (2011). AIAA 2011-2252

[35] K.D. Dahm, P.S. Virk, R. Bounaceur, F. Battin-Leclerc, P.M. Marquaire, R. Fournet, et al., Experimental and modelling investigation of the thermal decomposition of ndodecane, J. Anal. Appl. Pyrol. 71 (2004) 865-881.

[36] N. Gascoin, G. Fau, J. Bioud, P. Gillard, Permeation of inert and supercritical reactive fluids through metallic and composite media., 46th AIAA/ASME/SAE/ASEE Joint Propulsion Conference \& Exhibit. (2010). AIAA 2010-6551 
Table 1. Pyrolysis products distribution and paramaters (in wt.\%) at locations A (upstream),

$510 \mathrm{~B}$ (inside) and $\mathrm{C}$ (downstream) analyzed by GC/MS as a function of the maximum fluid 511 temperature.

512 Table 2. Comparison of pyrolysis parameters (in wt.\%) with or without porous medium 513 considering similar conditions

514 Table 3. Comparison of pyrolysis products (in wt.\%) with or without porous medium 515 considering similar decomposition rates

Figure 1. Schematic of the apparatus to be inserted in the furnace with representation of the 519 sensors.

Figure 2. a) Stainless steel porous medium: Fe (62 wt.\%), Cr (18 wt.\%), Ni (11 wt.\%) C (7 wt.\%), O (1 wt.\%) and Si 1 wt.\%. b) Visualization by SEM (4000 times magnification).

Figure 3. Type flow effect on the relationship between gasification and pyrolysis rate.

Figure 4. a) Coked porous medium. b) Visualization by SEM (5000 times magnification) and 524 EDS analysis: C (96 wt.\%), O (3.5 wt.\%) and Fe (0.5 wt.\%). c) After surface cleaning: Fe (52 wt.\%), C (20 wt.\%), Cr (14.5 wt.\%), Ni (9.5 wt.\%), O (2.5 wt.\%) and Si (1.5 wt.\%).

Figure 5. Time evolution of the mass of coke deposit with the one of methane production and the fuel temperature.

Figure 6. Relationship between coke formation and fluid temperature.

Figure 7. Variation of the Darcian term and estimated mass of coke.

Figure 8 . Relationship between coking activity and Darcian permeability. 


\begin{tabular}{|c|c|c|c|c|c|c|c|c|c|}
\hline \multirow{2}{*}{ Product } & \multicolumn{3}{|c|}{$725 \mathrm{~K}$} & \multicolumn{3}{|c|}{$765 \mathrm{~K}$} & \multicolumn{3}{|c|}{$820 \mathrm{~K}$} \\
\hline & $\mathrm{A}$ & $\mathrm{B}$ & $\mathrm{C}$ & $\mathrm{A}$ & $\mathrm{B}$ & $\mathrm{C}$ & $\mathrm{A}$ & $\mathrm{B}$ & $\mathrm{C}$ \\
\hline Hydrogen & $\sim$ & $\sim$ & 0,00 & 0,01 & 0,00 & 0,04 & 0,03 & 0,00 & 0,04 \\
\hline Methane & $\sim$ & $\sim$ & 1,28 & 0,38 & 0,10 & 1,33 & 1,16 & 0,33 & 2,16 \\
\hline Ethylene & $\sim$ & $\sim$ & 1,49 & 0,49 & 0,15 & 2,52 & 1,16 & 0,56 & 3,84 \\
\hline Ethane & $\sim$ & $\sim$ & 3,27 & 1,18 & 0,38 & 5,09 & 2,30 & 1,24 & 6,70 \\
\hline Propylene & $\sim$ & $\sim$ & 2,06 & 1,04 & 0,47 & 5,30 & 1,83 & 1,72 & 7,84 \\
\hline Propane & $\sim$ & $\sim$ & 2,42 & 1,26 & 0,68 & 5,99 & 1,88 & 2,31 & 7,17 \\
\hline But-1-ene & $\sim$ & $\sim$ & 1,00 & 0,48 & 0,42 & 2,46 & 0,77 & 1,21 & 4,45 \\
\hline Butane & $\sim$ & $\sim$ & 1,89 & 1,80 & 1,70 & 2,18 & 1,07 & 2,50 & 3,72 \\
\hline (E)-Pent-2-ene & $\sim$ & $\sim$ & 0,44 & 0,25 & 0,87 & 0,68 & 0,69 & 1,40 & 2,05 \\
\hline Pentane & $\sim$ & $\sim$ & 0,20 & 0,40 & 1,13 & 0,50 & 0,94 & 1,50 & 1,80 \\
\hline Cyclopentane & $\sim$ & $\sim$ & 0,00 & 0,00 & 0,00 & 0,00 & 0,00 & 0,00 & 0,01 \\
\hline Hex-1-ene & $\sim$ & $\sim$ & 0,50 & 0,64 & 2,01 & 0,67 & 1,10 & 2,27 & 1,95 \\
\hline Hexane & $\sim$ & $\sim$ & 0,17 & 0,33 & 1,00 & 0,19 & 0,44 & 1,04 & 0,58 \\
\hline Benzene & $\sim$ & $\sim$ & 0,00 & 0,01 & 0,03 & 0,00 & 0,08 & 0,01 & 0,08 \\
\hline Cyclohexene & $\sim$ & $\sim$ & 0,00 & 0,01 & 0,01 & 0,00 & 0,03 & 0,01 & 0,06 \\
\hline Hept-1-ene & $\sim$ & $\sim$ & 0,15 & 0,31 & 2,44 & 0,35 & 0,73 & 1,53 & 1,29 \\
\hline Heptane & $\sim$ & $\sim$ & 0,51 & 0,10 & 1,12 & 0,22 & 0,15 & 0,63 & 0,54 \\
\hline Toluene & $\sim$ & $\sim$ & 0,00 & 0,03 & 0,09 & 0,01 & 0,15 & 0,03 & 0,18 \\
\hline Oct-1-ene & $\sim$ & $\sim$ & 0,12 & 0,23 & 0,15 & 0,26 & 0,27 & 0,16 & 1,05 \\
\hline Octane & $\sim$ & $\sim$ & 0,09 & 0,12 & 0,10 & 0,12 & 0,18 & 0,12 & 0,27 \\
\hline Styrene & $\sim$ & $\sim$ & 0,00 & 0,00 & 0,00 & 0,00 & 0,00 & 0,00 & 0,00 \\
\hline p-Xylene & $\sim$ & $\sim$ & 0,00 & 0,00 & 0,01 & 0,00 & 0,02 & 0,00 & 0,03 \\
\hline Non-1-ene & $\sim$ & $\sim$ & 0,10 & 0,19 & 0,15 & 0,20 & 0,07 & 0,09 & 0,56 \\
\hline Ethylbenzene & $\sim$ & $\sim$ & 0,00 & 0,00 & 0,00 & 0,00 & 0,00 & 0,00 & 0,03 \\
\hline Nonane & $\sim$ & $\sim$ & 0,11 & 0,09 & 0,04 & 0,14 & 0,00 & 0,15 & 0,26 \\
\hline Dec-1-ene & $\sim$ & $\sim$ & 0,14 & 0,00 & 0,00 & 0,31 & 0,00 & 0,00 & 1,05 \\
\hline Decane & $\sim$ & $\sim$ & 0,00 & 0,07 & 0,05 & 0,07 & 0,10 & 0,06 & 0,00 \\
\hline Undec-1-ene & $\sim$ & $\sim$ & 0,04 & 0,07 & 0,01 & 0,07 & 0,00 & 0,00 & 0,14 \\
\hline Undecane & $\sim$ & $\sim$ & 0,09 & 0,19 & 0,13 & 0,17 & 1,53 & 0,15 & 0,19 \\
\hline Dodec-1-ene & $\sim$ & $\sim$ & 0,00 & 0,00 & 0,00 & 0,00 & 0,00 & 0,00 & 0,33 \\
\hline Dodecane & $>99$ & $>99$ & 83,84 & 90,25 & 86,70 & 71,04 & 83,31 & 80,92 & 51,57 \\
\hline Tridec-1-ene & $\sim$ & $\sim$ & 0,00 & 0,01 & 0,00 & 0,01 & 0,00 & 0,00 & 0,00 \\
\hline Tridecane & $\sim$ & $\sim$ & 0,01 & 0,03 & 0,02 & 0,03 & 0,00 & 0,02 & 0,04 \\
\hline Tetradecane & $\sim$ & $\sim$ & 0,01 & 0,02 & 0,01 & 0,02 & 0,00 & 0,02 & 0,02 \\
\hline Gasification rate & 0,00 & 0,00 & 13,50 & 6,00 & 10,00 & 26,00 & 10,00 & 15,00 & 39,00 \\
\hline Pyrolysis rate & $<1$ & $<1$ & 16,16 & 9,75 & 13,30 & 28,96 & 17,00 & 19,00 & 48,43 \\
\hline $\mathrm{H} / \mathrm{C}$ ratio & - & - & 0,2011 & 0,2011 & 0,1846 & 0,2050 & 0,2025 & 0,1916 & 0,1982 \\
\hline
\end{tabular}




\begin{tabular}{c|c|c|c|c} 
Type of reactor & \multicolumn{2}{|c|}{ Tubular reactor } & $\begin{array}{c}\text { Through porous } \\
\text { medium }\end{array}$ & Tubular reactor \\
\hline $\begin{array}{c}\text { Experimental } \\
\text { conditions }\end{array}$ & $\begin{array}{c}914 \mathrm{~K}, 10 \mathrm{bar}, \\
50 \mathrm{mg} / \mathrm{s}\end{array}$ & $\begin{array}{c}896 \mathrm{~K}, 10 \mathrm{bar}, \\
100 \mathrm{mg} / \mathrm{s}\end{array}$ & $\begin{array}{c}850 \mathrm{~K}, 35 \mathrm{bar}, \\
65 \mathrm{mg} / \mathrm{s}\end{array}$ & $\begin{array}{c}916 \mathrm{~K}, 60 \mathrm{bar}, \\
100 \mathrm{mg} / \mathrm{s}\end{array}$ \\
\hline \hline Dodecane & 91,61 & 99,58 & 51,57 & 96,44 \\
\hline Gasification rate & 7,40 & 0,00 & 39,00 & 1,00 \\
\hline Pyrolysis rate & 8,39 & 0,42 & 48,43 & 0,04
\end{tabular}


Tubular reactor

Through porous medium Tubular reactor \begin{tabular}{c|c|c|c}
\hline $1328 \mathrm{~K}, 10 \mathrm{bar}, 50 \mathrm{mg}$ & $1359 \mathrm{~K}, 10 \mathrm{bar}, 100 \mathrm{mg}$ & $850 \mathrm{~K}, 35 \mathrm{bar}, 65 \mathrm{mg}$ & $1280 \mathrm{~K}, 60 \mathrm{bar}, 100 \mathrm{mg}$ \\
\hline
\end{tabular}

\begin{tabular}{|c|c|c|c|c|}
\hline & $1328 \mathrm{~K}, 10$ bar, $50 \mathrm{mg}$ & $1359 \mathrm{~K}, 10 \mathrm{bar}, 100 \mathrm{mg}$ & $850 \mathrm{~K}, 35$ bar, $65 \mathrm{mg}$ & $1280 \mathrm{~K}, 60 \mathrm{bar}, 100 \mathrm{mg}$ \\
\hline Hydrogen & 0,00 & 0,03 & 0,04 & 0,01 \\
\hline Methane & 4,91 & 2,32 & 2,16 & 1,18 \\
\hline Ethylene & 13,06 & 4,68 & 3,84 & 1,03 \\
\hline Ethane & 6,90 & 2,60 & 6,70 & 1,79 \\
\hline Propylene & 14,47 & 4,69 & 7,84 & 2,49 \\
\hline Propane & 1,65 & 1,68 & 7,17 & 2,34 \\
\hline But-1-ene & 0,00 & 3,79 & 4,45 & 1,79 \\
\hline Butane & 4,80 & 1,07 & 3,72 & 1,68 \\
\hline (E)-Pent-2-ene & 0,00 & 2,62 & 2,05 & 2,22 \\
\hline Pentane & 3,00 & 4,53 & 1,80 & 3,33 \\
\hline Hex-1-ene & 0,06 & 1,43 & 1,95 & 2,98 \\
\hline Hexane & 0,04 & 0,28 & 0,58 & 1,40 \\
\hline Benzene & 0,00 & 0,00 & 0,08 & 0,08 \\
\hline Hept-1-ene & 0,00 & 0,00 & 1,29 & 1,74 \\
\hline Heptane & 0,01 & 0,02 & 0,54 & 0,42 \\
\hline Oct-1-ene & 0,06 & 0,08 & 1,05 & 0,96 \\
\hline Octane & 0,01 & 0,01 & 0,27 & 0,39 \\
\hline Toluene & 0,00 & 0,00 & 0,18 & 0,13 \\
\hline Non-1-ene & 0,37 & 0,43 & 0,56 & 0,61 \\
\hline Nonane & 0,04 & 0,07 & 0,26 & 0,41 \\
\hline Dec-1-ene & 1,42 & 1,24 & 1,05 & 0,69 \\
\hline Decane & 0,11 & 0,14 & 0,14 & 0,16 \\
\hline Undec-1-ene & 0,41 & 0,39 & 0,19 & 0,20 \\
\hline Undecane & 0,00 & 0,14 & 0,33 & 0,36 \\
\hline Dodecene & 0,00 & 0,06 & 0,00 & 0,06 \\
\hline Dodecane & 48,67 & 67,71 & $\mathbf{5 1 , 5 7}$ & 71,26 \\
\hline Gasification rate & 41,00 & 25,50 & 39,00 & 15,00 \\
\hline Pyrololysis rate & 51,33 & 32,29 & 48,43 & 28,74 \\
\hline
\end{tabular}




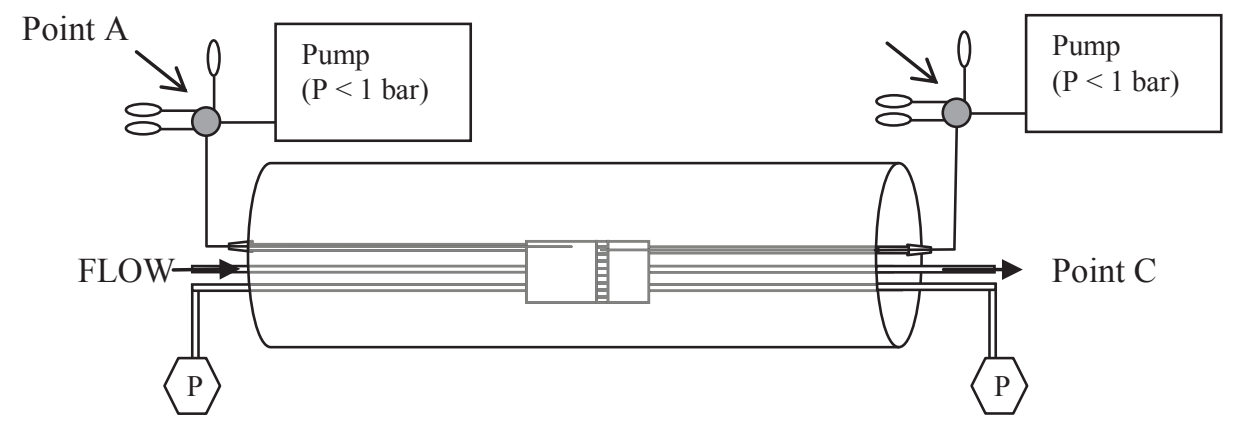

P Pressure sensor $\bigcirc$ Valve 5-ways $\bigcirc$ Sampling cylinder 

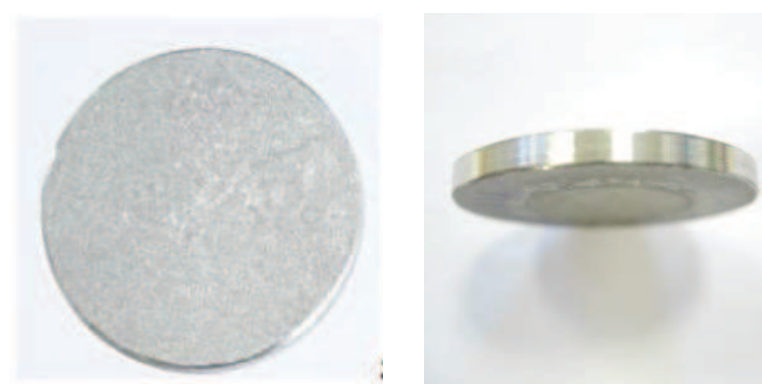

a)

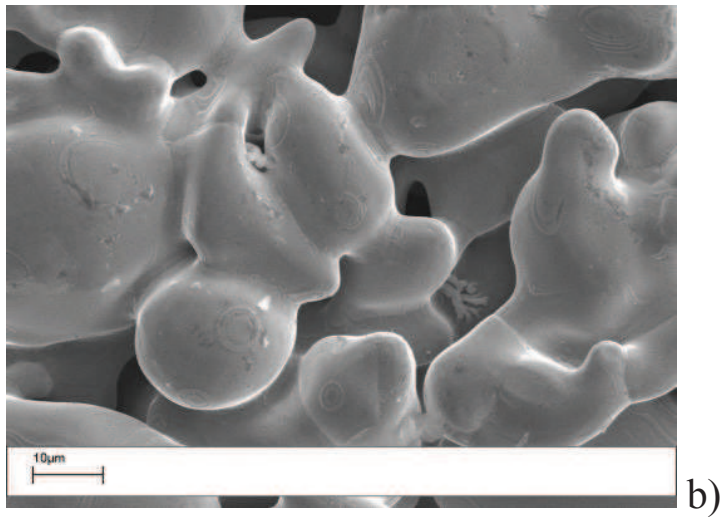

Page 27 of 34 


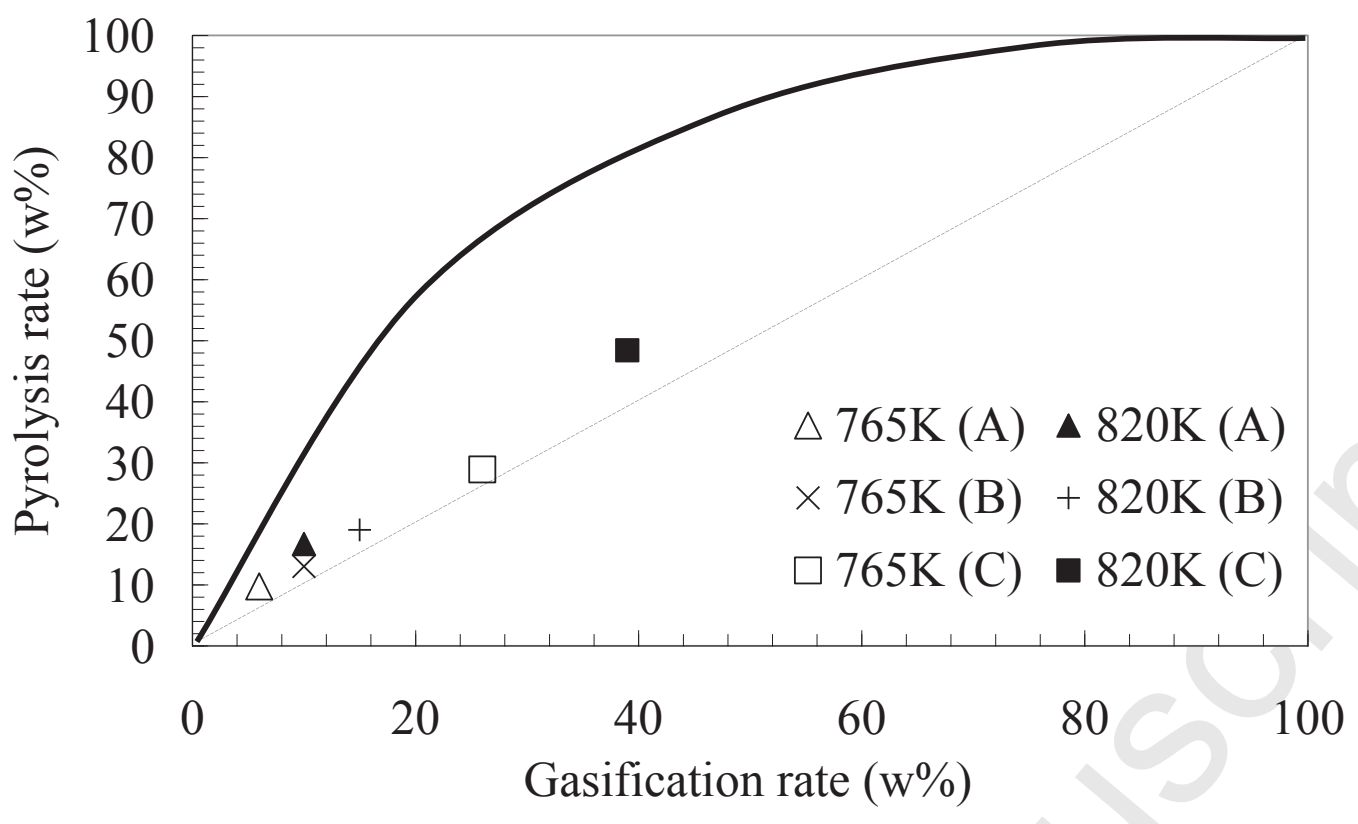


a)
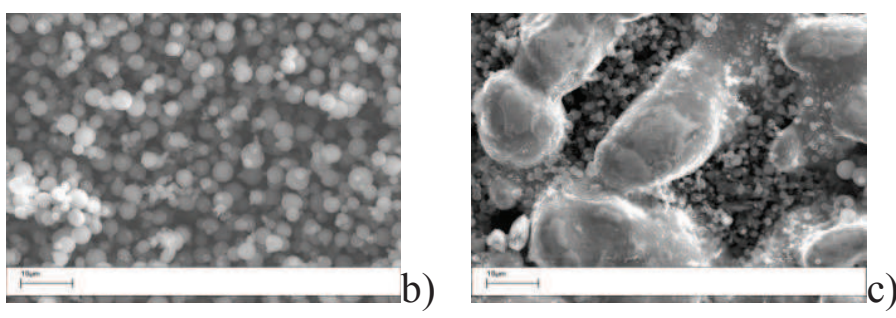


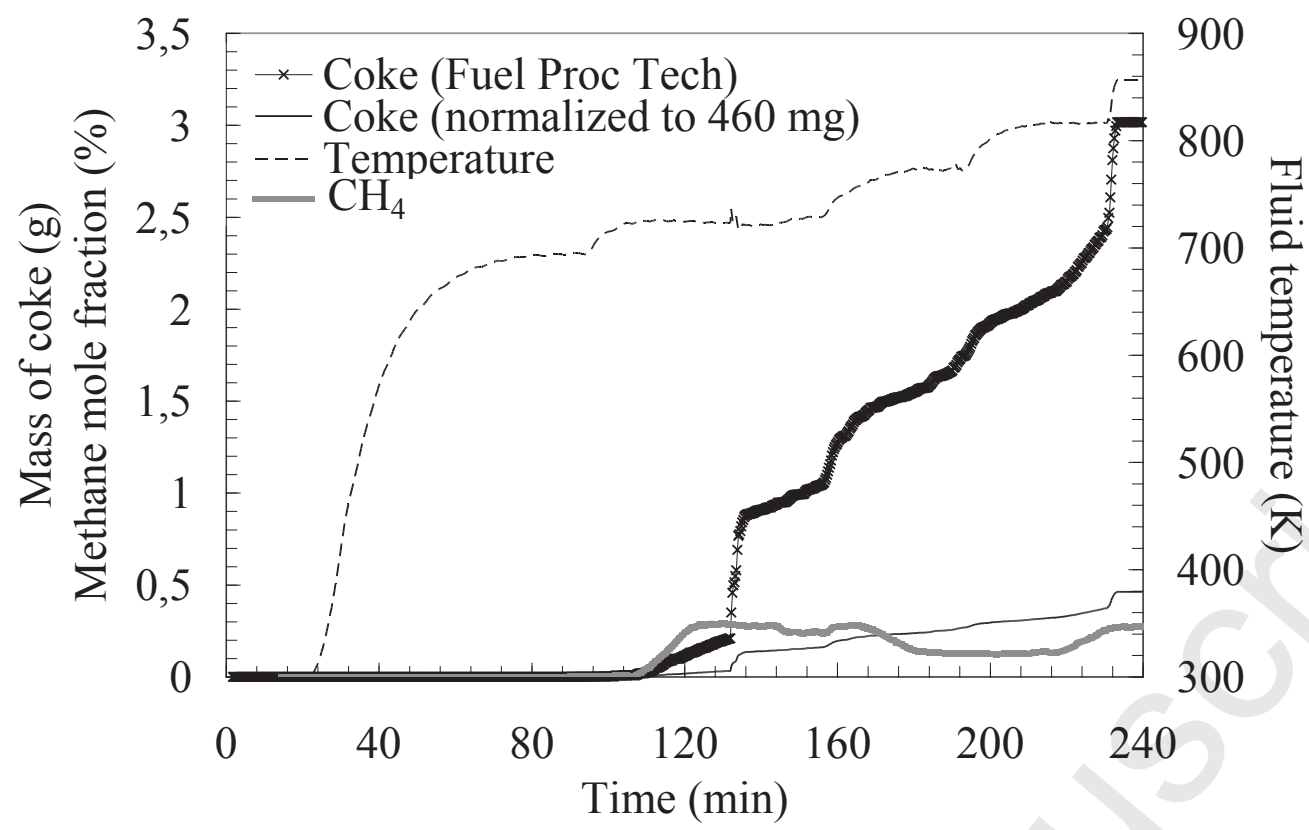




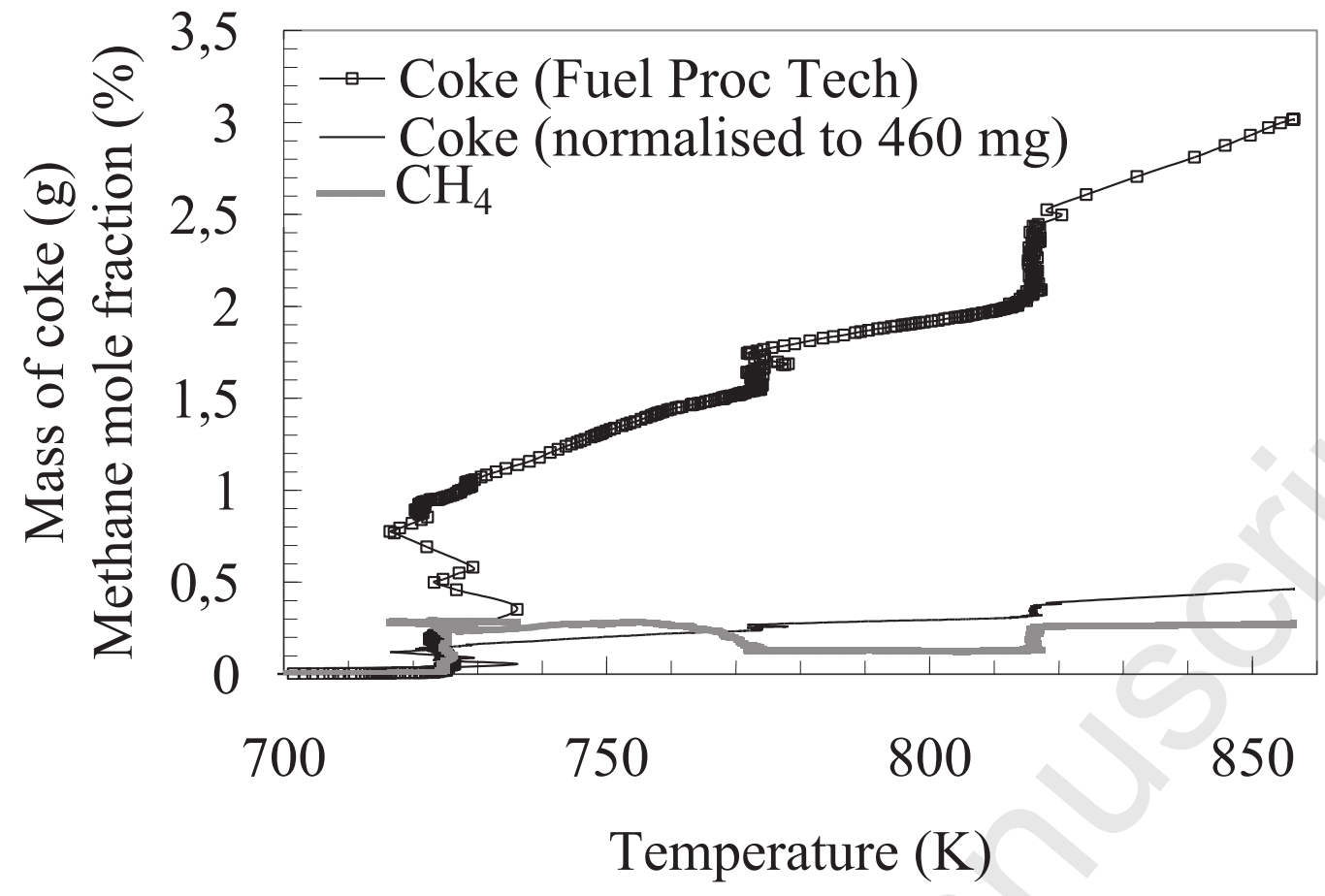




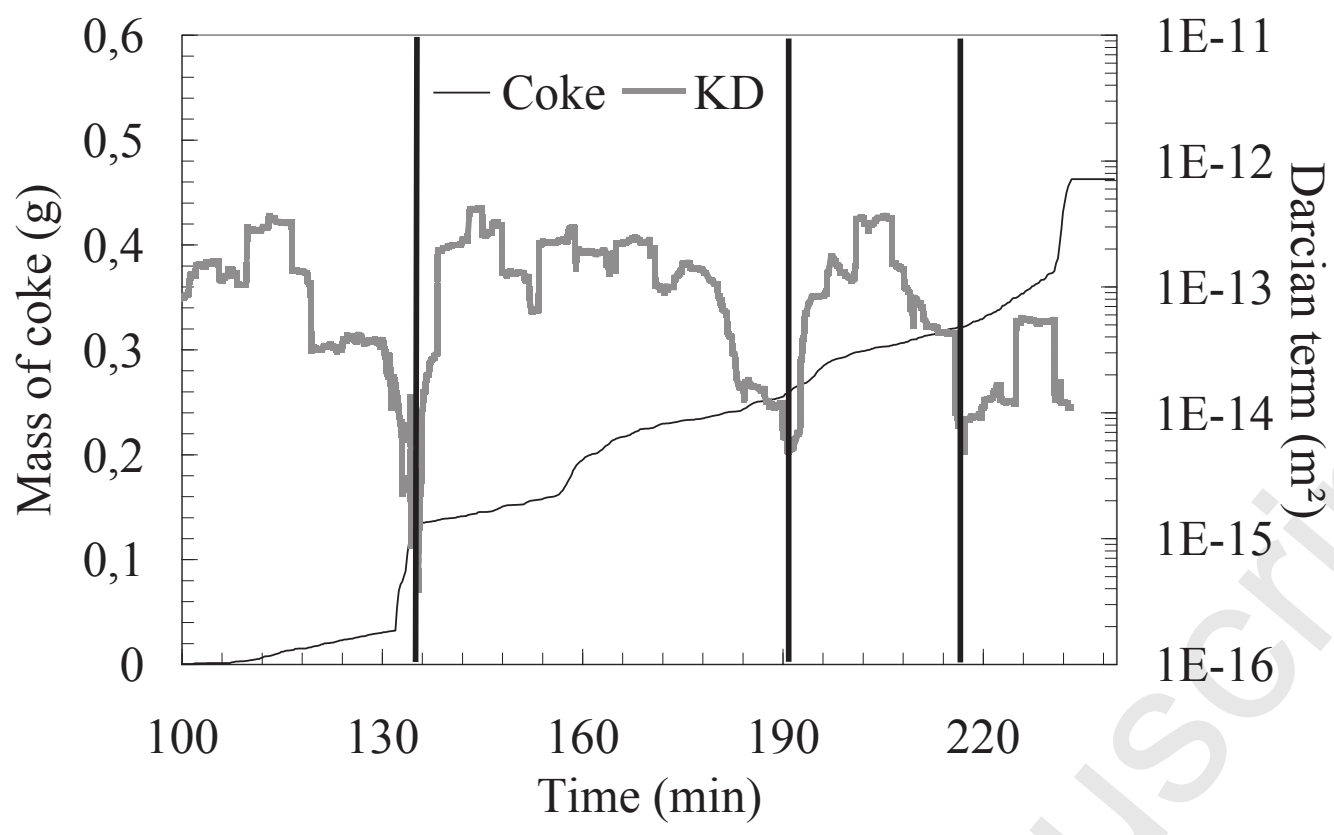




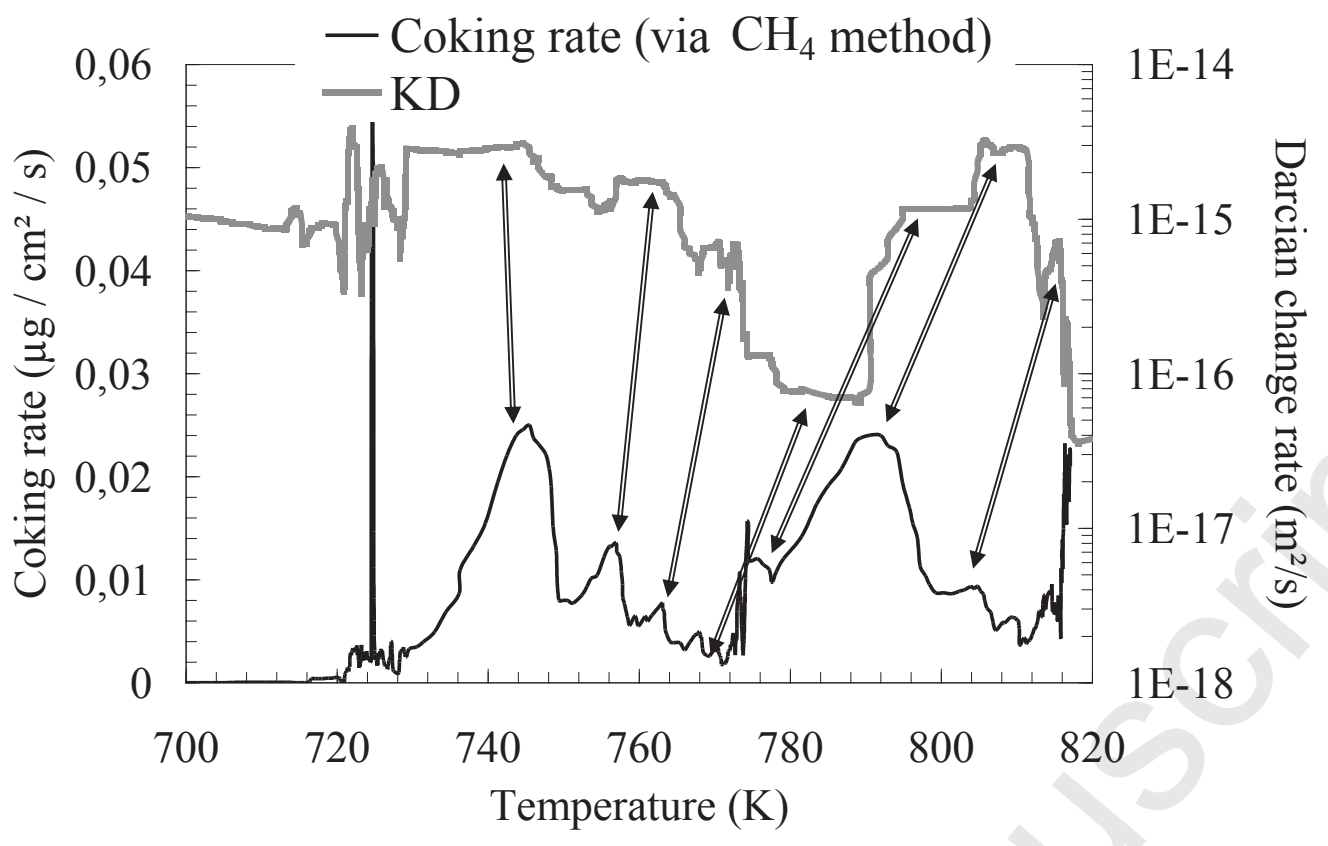




\section{Highlights}

- Hydrocarbon fuel pyrolysis achieved under supercritical state through porous medium

- Spatial profiles of pyrolysis mixture composition obtained for three temperatures

- Unusual production of alkenes, of light species and of coke due to porous medium

- Transient relationship proposed between coke deposit and permeability changes

- Contact surface effect shown through comparisons between plug flow and porous flow 